\title{
The Correlation between Energy Cost Share, Human, and Economic Development: Using Time Series Data from Australasia, Europe, North America, and the BRICS Nations
}

\author{
Ryan Roberts ${ }^{1,2, *}$, Josephine Kaviti Musango ${ }^{2}$, Alan Colin Brent ${ }^{3,4}(\mathbb{C}$ and \\ Matthew Kuperus Heun ${ }^{5}$ (D) \\ 1 Deutsche Gesellschaft für Internationale Zusammenarbeit (GIZ) GmbH, Pretoria 0083, South Africa \\ 2 School of Public Leadership, Urban Modelling and Metabolism Assessment, Centre for Complex Systems in \\ Transition, Stellenbosch University, Stellenbosch 7600, South Africa; jmusango@sun.ac.za \\ 3 Department of Industrial Engineering, Centre for Renewable and Sustainable Energy Studies (CRSES), \\ uMAMA, Centre for Complex Systems in Transitions (CST), Stellenbosch University, Stellenbosch 7600, \\ South Africa; acb@sun.ac.za \\ 4 Sustainable Energy Systems, Engineering and Computer Science, Victoria University of Wellington, \\ Wellington 6140, New Zealand; alan.brent@vuw.ac.nz \\ 5 Engineering Department, Calvin College, Grand Rapids, MI, USA; mkh2@calvin.edu \\ * Correspondence: ryan2roberts@yahoo.com; Tel.: +27-83-661-0634
}

Received: 20 July 2018; Accepted: 4 September 2018; Published: 12 September 2018

\begin{abstract}
This paper investigates how a change in a region's energy cost share (ECS), a ratio of a region's energy expenditure as a fraction of its gross domestic product (GDP), affects the region's social and economic development. Nations from four regions of the world, namely Australasia, Europe, North America, and the BRICS nations (Brazil, Russia, India, China, and South Africa) were chosen for this study. Using time series data from the period of 1978 to 2010, the annual ECS of each country was compared to the year-on-year GDP change, as well as the components of the human development index (HDI). High ECS values were seen to correlate with low economic development. The existence of an ECS threshold was found in 14 of the 15 countries, for all the regions, and for the worldwide analysis, with very strong correlation coefficients obtained for periods of high ECS. New to this field of research, this study also investigated the effects of ECS on gross national income (GNI) per capita change, as well as the effects of $0,1,2$, and 3 year lags. This investigation found that ECS has a very strong correlation to GNI per capita change, which was much stronger than the correlation between ECS and GDP change. The effects of ECS on social and economic development occurred after varying time lags, and it is unique to each country and region. Regions with similar ECS dynamics were identified, with possible reasons for the similarities being provided.
\end{abstract}

Keywords: economic development; energy; energy cost share; social development; sustainability

\section{Introduction}

Rising global temperatures and fossil fuel depletion have created an urgency for a shift towards clean energy. While the subsequent environmental benefits have been well documented, a blind eye cannot be turned on the social and economic challenges facing many nations today. A transition to cleaner energy sources would most likely lead to a change in energy costs, which would impact the society and the economy of many nations and regions. The goal of this paper is to investigate the effects of the energy cost share (ECS), a ratio of energy expenditure to gross domestic product (GDP), 
on social and economic development. This is vital to understand in order to construct the energy and environmental policies that can advance society in a sustainable manner.

\subsection{Socio-Economic Effects of Energy}

Currently, mainstream economic thinking tends to neglect the importance of energy, chiefly because it is not identified as a primary factor of production, such as labour and capital [1-4]. The role of energy, more specifically energy consumption, as an essential driver of economic growth is acknowledged by ecological economists [1]. However, there is no a consensus among economists of the role that energy consumption plays [4]. Ozturk [4] conducted a survey of the recent progress in the literature on the energy consumption-economic growth and electricity consumption-economic growth causality nexus. The findings showed conflicting results and there was no consensus on the existence of a link between energy consumption and GDP within the existing literature. Recommendations were made for scholars in the field to focus on new approaches. Heun et al. [3] used different methods to model the effects of energy in the economy by using aggregate production functions (APFs), commonly used by mainstream economists. Their findings revealed that the lack of standard modelling approaches, modelling evaluations, and parameter precisions can lead to different interpretations of the economy, and thus to different energy policies. This confusion not only affects the development and quality of life for people worldwide, but is also occurring in the midst of environmental challenges, such as climate change [4]. The method of analysing the effects of energy in the economy still needs a great deal of effort, with the study proposing a significant list of future work. Other approaches, using models other than APFs, are worth exploring.

Although GDP is a fairly plausible indicator of measuring the economic growth on a regional, national, or global scale, it fails to identify the quality and the distribution of said growth. There is the view that the world's addiction to increasing GDP is the main reason for why many social inequalities are still experienced [5]. Fioramonti [6] points out many of the flaws of solely using GDP as a policy-making tool. The United Nations has used a different indicator, the human development index (HDI), to measure human development in nations across the world. It gives an aggregated score between 0 and 1 for each country, and it takes into consideration mean and expected years of schooling, and life expectancy, as well as gross notational income (GNI) per capita, or purchase power parity (PPP). Although the weightings of each component, as well as the exclusion of other indices are very subjective, the GNI metric provides a much better view of human development and is commonly accepted [7].

Access to energy, more specifically electricity, has been identified as a key factor in poverty alleviation [8-11]. Nkomo [11] found a strong link when analysing HDI levels and net energy consumption per capita, using cross-sectional data from the Southern Africa Development Community (SADC) region. The use of cross-sectional data could be one reason for why these conclusions, differing from Ozturk [4], were made. Kanagawa \& Nakata [9] show the links between energy access and human development components. Due to the scalability of clean energy systems, it is possible to make a huge impact on areas where grid connection is not possible or feasible. However, these studies [8-10] focus purely on access to energy. If all energy sources were replaced with renewables (i.e., swap solar energy for coal energy, bioethanol for diesel), energy accessibility would still be a problem.

Current concerns regarding a transition to clean energy sources are the availability and cost. Given the range of energy storage technologies that are available (battery storage, pumped hydro, thermal storage, and so forth), a constant supply of energy can be supplied at a cost. Therefore, analysing the change in cost of energy, and not the pure consumption of energy, should give a better indication of its effects on an economy and on human development, leading to the reason for why Ozturk [4] found a lack of consensus in the literature for the link or the direction of causality between energy consumption and economic growth. A different set of metrics or models, which incorporate the price of energy sources, needs to be used. 


\subsection{Energy Metric Analysis}

Studies using economic and biophysical metrics to analyse the effects of energy on economic development do exist, albeit on a smaller scale. Bashmakov [12] proposed three laws of energy transitions. The first provides great insight into the dynamics of energy cost and economic growth. It states that energy expenditure to GDP ratios, known as ECS, have remained relatively stable over decades, and are very similar across regions and large countries. ECS reflects the percentage of money that is spent on energy to generate to run the economy. The ECS of a country or region and for a particular period, $x$, can be calculated as follows:

$$
E C S_{x}=\frac{\text { Monetary Expenditure on Energy }}{\text { Gross Domestic Product }} x
$$

Furthermore, Bashmakov's first proposition states that ECS-to-income ratios have also remained stable. Bashmakov [12] posits that there is no correlation between energy costs, income levels, and economic activity, so long as an ECS threshold is not exceeded. If the values of ECS go beyond the indicated ECS threshold, GDP growth becomes highly dependent on ECS, and eventually reduces as a result of high ECS. The deceleration of GDP reduces energy demand, decreasing consumption and price, until the ratio is stable again. The increase in energy costs force consumers to become either more efficient or to reduce their consumption, leading to a reduction in output. The demand for energy then slows, which in turn drives down the cost of energy and leads to a lower ECS. Once the ECS threshold is reached, energy supplier's revenues are limited by the rate of economic growth; thus a price increase by $1 \%$ leads to a reduction in demand by more than $1 \%$ [12]. The high prices make it favourable for accelerated energy production, further reducing the demand and eventually the cost. Bashmakov [12] found an ECS threshold of between 8-10\% for the US and $9-11 \%$ for Organisation for Economic Co-operation and Development (OECD) countries using primary energy cost data. This study estimates an energy cost threshold for the final energy consumption to be much lower, at around $4-5 \%$ for the US and $4.5-5.5 \%$ for OECD countries. The study pinpoints energy cost shares to GDP growth and income levels as important metrics to monitor. Bashmakov [12] provides a relationship between ECS and economic growth, as well as a partial relation between ECS and human development. Bashmakov [12] provides only a general threshold for OECD countries which not suitable enough for policy makers at a national or regional level.

Consideration must be given to the fact that these ECS thresholds may be different from country to country, depending on whether it is a net importer or exporter of energy, and the ECS thresholds could change with time. More so, energy policies are generally made on a national or regional level, and not on a worldwide scale. Some countries, such as South Africa for example, have a central energy planning system, whereby the optimum energy mix for the nation is modelled based on a range of factors, such as energy cost and socio-economic benefits. ECS thresholds can be incorporated into these models, ensuring that an energy mix with a certain ECS does not negatively affect social or economic development. Other countries with open energy markets, such as those seen in the European nations, have less control over the type of energy that is being used. However, taxes and subsidies can be used by the government to promote certain types of energy sources, or to ensure that an ECS threshold is not surpassed.

Aucott \& Hall [2] further echoed the ideas of Bashmakov [12] with regard to the energy cost-economic growth nexus. If economic performance is solely analysed and energy cost is not a significant driver of economic performance, then low energy costs should be associated with slow economic development. This is so because, in theory, less economic activity would lead to less demand for products, and ultimately a reduction in price. Conversely, if energy costs are related to economic growth, then low economic development should be characterised by an increase in energy costs [2]. Aucott \& Hall [2] also compared the ECS of the US to the year-on-year change in GDP. The cost to obtain primary fuel sources (coal, oil, natural gas and nuclear ore) were used in calculating the ECS. Using statistical tests, a correlation between the ECS and economic growth was found. Analysing a 
period from 1950 to 2013, the study suggested the ECS threshold to be around $4 \%$. Above this, weak economic performance is likely to occur. The problem with using expenditures on primary fuel to calculate ECS is that it does not provide the price that is paid by consumers at the point of consumption. This omits the processing and transportation costs that are unique to each source, which influence the final price that is paid by consumers. New methods of extracting energy are being explored, and governments heavily subsidise specific energy markets. Assuming that variations in primary fuel costs will have an equal change in the final price paid by consumers precludes the consideration of the changes occurring to these intermediary processes.

King [13] provides a correlation analysis between ECS and economic growth. Points of consumption prices for different fuels such natural gas, coal, petroleum, and electricity were used to calculate the ECS, and it was also compared to the year-on-year change in economic growth. As the final price is what is experienced by the economy, it is reasonably robust to assume to that these prices will affect economic growth [13]. The same argument can be made for human development. Using data from 1978-2010 and 44 countries as a representation of the globe, the results showed a statistically significant negative correlation to ECS, and a one-year lag in GDP. This indicates that ECS is an important factor in global economic growth. The Pearson's correlation coefficient calculated in King [13] for each country showed the sensitivity that ECS has on each country. However, most of the correlation coefficients were not statistically significant, which may be due to the lack of accurate time series data available. The International Energy Agency (IEA) has a significantly rich database of energy consumption and prices, although there are large amounts of missing data points. King [13] provided a suitable methodology to estimate this data. Secondly, and more importantly, this study gives a general overview of the correlation of ECS and GDP over the time. Bashmakov [12] revealed that energy prices play little role in influencing economic growth in general terms. It is only when energy expenditure reaches an upper threshold that it restrains the factors contributing to economic growth, such as labour and capital. If Bashmakov is correct, critical energy cost shares, identified by Bashmakov [12] and Aucott \& Hall [2] are perhaps more important than general correlation coefficients.

Fizaine \& Court [14] conducted a similar study to King [13] where they estimate ECS for the US and the world economies from 1850 to 2012. The authors recognise the importance of including biomass in energy expenditure. More than 2.7 billion people are estimated to rely on fossil fuels for energy sources, most of these coming from developing Asia and sub-Saharan Africa [15]. The use of this energy contributes heavily to global warming, deforestation, and respiratory illness levels [16]. If a transition away from $\mathrm{CO}_{2}$-based energy sources towards cleaner fuels is to be achieved, it is vital to consider biomass. The study goes one step further than the correlation test performed by King [13], and uses performs Granger causality tests for different variables of the US economy, such as oil expenditure, GDP growth, unemployment rate, and capital formation. The results showed there is a statistically significant negative Granger causality from oil expenditure (oil cost share) to GDP growth from 1960 to 2010; an important finding, as previous correlation studies only identify a relationship between ECS and economic growth. Fizaine \& Court [14] prove that a high expenditure on oil causes low growth in the US. A similar negative causality was found for total energy expenditure and GDP growth; however, the limited amount of data points could not produce statistically significant results.

Arshad et al. [17] developed a macroeconomic model to examine the impact of energy prices on economic growth in Pakistan. The paper showed that an increase in energy prices negatively affects stock prices, inflation, and the productivity of the economy. The decline in these three indices further affected real wage rate and government spending and it led to more unemployment. Although the paper makes no mention of possible energy expenditure thresholds, there is evidence that ECS affects societal and economic growth. Murphy \& Hall [18] suggest that "when energy prices increase, expenditures are re-allocated from areas that had previously been added to GDP." This suggestion may also apply to social structures that indirectly affect economic growth and is worth investigating. Although access to energy plays a key role in alleviating poverty [8-11], it was unrecognised as a factor of poverty, being excluded in the Millennium Development Goals. The exclusion of energy may 
explain why an enormous gap in the literature regarding energy costs and human development exists, making it more difficult for policy-makers to develop energy plans that benefit society.

\subsection{Summary of Literature and Objectives of the Paper}

While the links between energy and the environment have been well documented, much less has been made of the effect of energy on social and economy development. From the literature reviewed, it was established that mainstream economists disregard energy from constituting a major part in economic growth, similar to labour and capital [1,2]. Mainstream economists fail to consider the possibilities that inexpensive energy can create in society, as well as the extreme dependence that modern day society has on energy. Previous literature that has compared energy consumption to economic growth, shows that the causality between energy and economic growth is ill-defined. Energy metrics, such as energy cost share, show a much stronger link between energy and the economy $[2,13,17]$. If a smooth transition towards clean energy technologies is the end goal, this relationship is even more important, as studies have shown that renewable energy development is more likely to occur in countries that have a stable growth of around $4 \%$ per year $[19,20]$. These studies provide valuable information, but they fail to provide a complete picture of the dynamics between energy and the economy that is needed by policymakers to transition towards a clean energy strategy. There is also very little literature comparing energy metrics to human development.

The objectives of the paper are thus to: identify the correlation between energy cost share and economic growth for selected countries from different regions; to identify the correlation between energy cost share and human development for selected countries from different regions; to investigate the effects of multiple-year lags on the correlations; and to conduct a regional analysis of country data.

\section{Research Methodology}

\subsection{Country Selection for Investigation}

The choice of nations to be analysed was largely dependent on the need to undertake a comparative analysis between regions and countries of different continents, as well as the data availability. The five largest countries, economically, were chosen to represent Europe. Due to data limitations for Africa, Asia, and South America, the BRICS nations that are seen as upcoming economic players were included as a representation of the 'Global South'. The use of these nations obviously gives a very poor representation of the nations in their respective continents, as they are the economic leaders. However, the choice was influenced by data availability. The countries selected from each region for the investigation are shown in Table 1.

Table 1. Countries chosen for analysis per region.

\begin{tabular}{cccc}
\hline Australasia & Europe & North America & BRICS \\
\hline Australia & France & Canada & Brazil \\
New Zealand & Germany & Mexico & Russia \\
& Italy & United States of America & India \\
& Spain & & China \\
& United Kingdom & & South Africa \\
\hline
\end{tabular}

\subsection{ECS Data}

The ECS data used was the same estimated ECS data used by King [13]. In this analysis, the IEA database was used for price and consumption data. The database provides national price and quantity data for three sectors (industrial, electricity, and residential) for natural gas and coal (separated into five coal types), and for two sectors (industrial and residential) for electricity and oil (separated into eight products in total). The energy prices used in calculating the ECS are 12 month average prices from the IEA database. Taking the average energy prices will assist in negating the effect that outlying 
price data points will have on the results. Even though this was the most comprehensive database of energy, there were still large amounts of price and quantity data missing, especially from Third World countries. A methodology to allocate the prices to the missing points is established by King [13], to obtain an ECS estimate. Using this ECS data generated would give comparable results, as well as allowing country and regional comparisons.

\subsection{GDP Data}

The annual change in GDP growth for each of the nations from 1978 to 2015 was obtained from the World Bank database [21]. The GDP data for Russia pre-1991 was obtained from the OECD database [22].

\subsection{GNI Per Capita Data}

The annual change in the GNI per capita change for each of the nations from 1978 to 2015 was obtained from the World Bank database [21]. The annual change in GDP per capita growth was allocated in the event of missing data points. This applied in the following circumstances:

China: 1978-1990;

New Zealand: 1978-1998;

Russia: 1978-1990.

\subsection{HDI Indices}

The data required to calculate the life expectancy index, namely life expectancy at birth, were extracted from the World Bank database [21]. The data required for the education index, represented by the mean and the expected years of schooling, was obtained from the United Nations Development Programme website [23]. Values for the mean and expected years of schooling are only monitored every fifth year from 1980-2005; thereafter it was captured every year. Proportional interpolations were used to fill in the missing data points from 1980 to 2005, showing the trend of the education index of that time period. This calculated the value for each year based on the change between the points collected every five years.

\subsection{Correlation Test}

Pearson's correlation tests were used to identify any patterns seen in the data. These tests provide a greater understanding of how the variables are related. It was decided to use this same method as King [13] to produce comparable results. As social and economic growth could also be affected by various factors; other than ECS, causality tests where not used at this stage. To establish whether the correlation found was statistically significant, the $p$-value for each correlation coefficient was also calculated. The null hypothesis $\mathrm{H}_{0}$ for this test was set at $\mathrm{r}=0$, and the alternate hypothesis $\mathrm{H}_{1}$ was $r \neq 1$. The $p$-value was dependent on two factors, the strength of the correlation of the existing data, as well as the sample size of the data set. From literature, it was established that the dataset may be limited, and a significance level of $10 \%$ was chosen for this study. Thus, a $p$-value $<0.1$ will ensure that null hypothesis is not rejected and that the correlation is statistically significant. The commonly used statistical analysis software package $\mathrm{R}$ was used to calculate these correlation coefficients.

\subsection{Analysis}

Once the data was obtained for the countries, a suitable method to establish any relationships was needed. Each nation was analysed using the following three-step process:

i Graphs comparing the ECS to economic and human indicators for the time series data were plotted for each country, each region, and for all countries. From these, an understanding of how each indicator trends in relation to a change in energy expenditure was obtained. Any patterns or thresholds were identified. 
ii Overall Pearson correlations for the entire time series data were established to confirm if there was a relation. Ccorrelation coefficients were then calculated, along with their corresponding $p$-values. This was done for zero, one, two, and three year lags being applied to GDP and GNI per capita change.

iii As ECS has a noticeable effect on the economy once a certain threshold has been exceeded [12], correlation coefficients were found over periods of time, where the ECS threshold established in (i) was calculated. This was done for the metrics where a correlation was identified.

The dynamics of ECS on the nations, regions, and all countries were first analysed by plotting the ECS against the selected economic and human development indicators for the entire time series given. Should any patterns be identified, a correlation test between ECS and the metrics was conducted. Time lags of $0,1,2$, and 3 years were applied to the economic and human development indices. Statistically significant results were those having $p$-values less than 0.1 . After this, the correlation test was conducted for periods of high ECS to establish any possible ECS thresholds. In a similar fashion, time lags of $0,1,2$, and 3 years were investigated. The strongest correlation found was published for the ECS threshold test with the lowest ECS value for the period investigated was used to estimate the ECS threshold. As no correlation between the health and education indices could be obtained, the results were omitted.

\section{Results and Discussions}

\subsection{Global Dynamics}

The ECS of the 15 countries, from 1978-2010, were plotted in Figure 1 next to the GDP and GNI per capita change. In order to determine whether data from the 15 countries used could give a good representation of global dynamics, the ECS data used by King [13] for a global analysis, using 44 countries making up approximately $95 \%$ of global GDP, was also plotted alongside the ECS data calculated in this study. A chi-square goodness-of-fit test was undertaken between the ECS metric calculated in this study, and model of King [13], with a result of 1 being returned. This indicates the data used in this model gives a good representation to that of King [13].

The shape of the ECS line seen in Figure 1 is similar for most countries analysed with high ECS peaks, occurring around 1980 and 2009. A high ECS peak above 10\% is found in 1980, followed by a rapid decrease over the next five years. This decline continues at a steady rate until the turn of the millennium. From this point, the ECS increases to a second ECS peak of above $8 \%$ in 2008 . Periods of low development are seen by both GDP and GNI per capita change after the two ECS peaks. These indices also dip in 1990, although this cannot be attributed to high ECS values. It is noted that the GNI per capita change line is below the economic growth line throughout the period of the graph, indicating that it will be affected more severely should ECS constrict growth. 


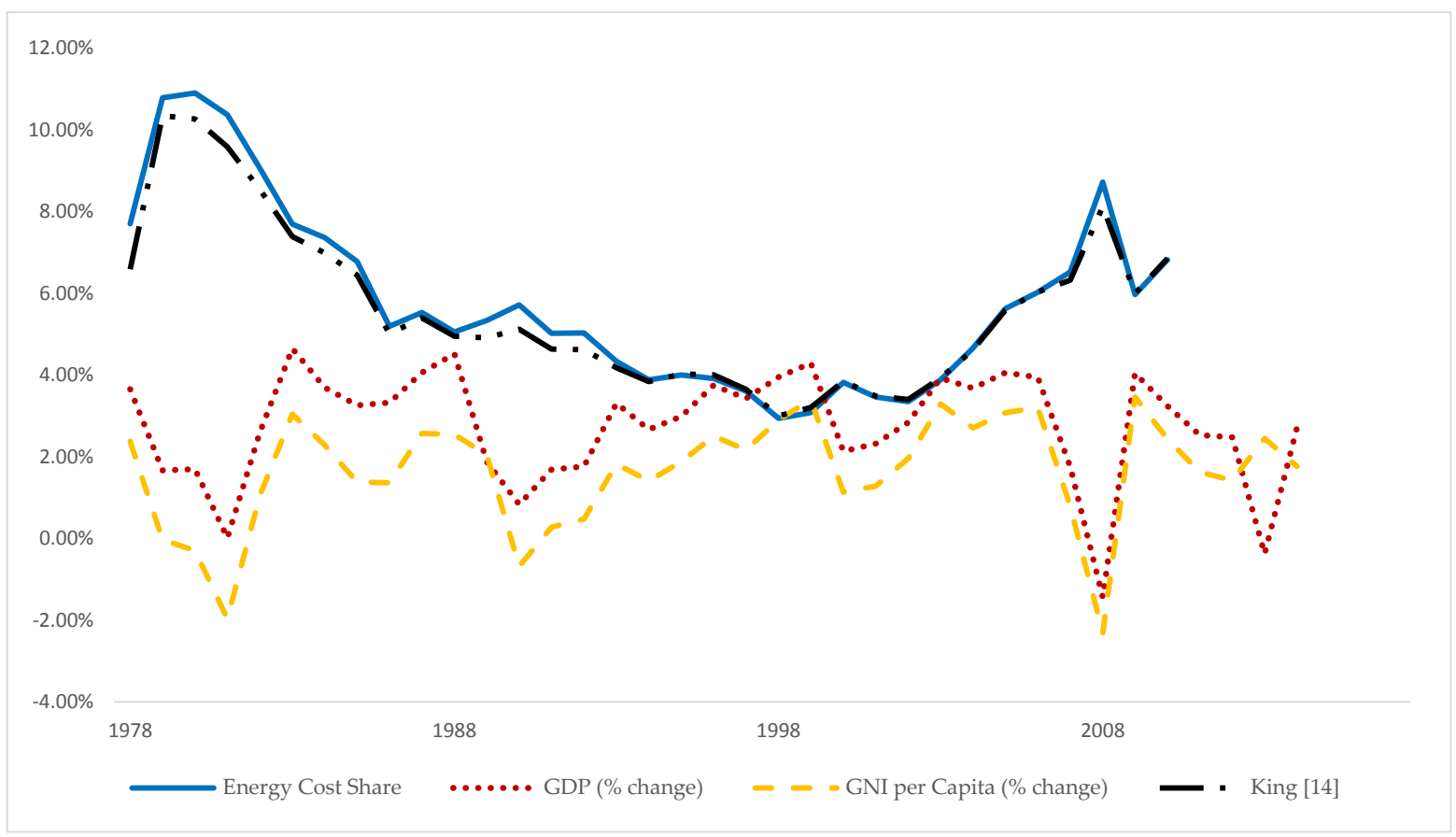

Figure 1. The combined gross domestic product (GDP) and gross national income (GNI) per capita and energy cost share (ECS) values for countries analysed were plotted over the time series. These countries represent 12 of the 15 current global leading economies (58\% of global GDP in 2015) and more than four billion people we must be mindful of the fact that only 15 countries are used. The ECS values from King [13], comprise 44 countries and making up 93-95\% of global GDP are also plotted.

\subsection{ECS vs Economic Development}

Tables 2 and 3 indicate an obvious relationship between ECS and the growth of economies. Significant correlations were established for 14 of the 15 countries analysed, all four of the regions, as well as the "All Countries" analyses. These relationships were discovered, even though all the countries analysed, especially the third world nations, have faced other issues throughout the period that may have disturbed the GDP change indices, but not the ECS values; for example, political instability. The significant correlations established were much stronger during periods of high ECS than for the overall period. The average correlation coefficient during periods of high ECS was -0.870 , which was much larger than the average overall correlation coefficient of -0.377 . This validates the proposition of Bashmakov [12] that states that the economy becomes highly dependent on ECS once a threshold has been exceeded. The threshold value of $4.9 \%$ obtained for the USA in this study are similar to the ones obtained by Bashmakov [12], Aucott \& Hall [2], and King [13].

Table 2. The results from the correlation tests between GDP change and ECS for the different countries, regions and all countries analysed. The strongest significant correlation, obtaining a $p$-value of less than 0.1 , is published, with its corresponding $p$-value. The year lag where this correlation was obtained is also published alongside. As significant correlations could be obtained for multiple year lags, the year lags applied to GDP change that produced significant results are displayed in the last column. Insignificant correlations were not published.

\begin{tabular}{ccccc}
\hline Country & Strongest Correlation Coefficient & $\boldsymbol{p}$-Value & Year Lag & Year Lags Affected \\
\hline Australia & -0.304 & 0.086 & 1 & 1 \\
Brazil & - & - & - & - \\
Canada & -0.319 & 0.070 & 1 & 1 \\
China & - & - & - & - \\
France & -0.340 & 0.053 & 1 & 1 \\
\hline
\end{tabular}


Table 2. Cont.

\begin{tabular}{ccccc}
\hline Country & Strongest Correlation Coefficient & $p$-Value & Year Lag & Year Lags Affected \\
\hline Germany & - & - & - & - \\
India & - & - & - & - \\
Italy & -0.351 & 0.045 & 1 & 1,2 \\
Mexico & - & - & - & - \\
New Zealand & - & - & - & - \\
Russia & - & - & - & - \\
South Africa & - & - & - & $0,1,2,3$ \\
Spain & -0.661 & $2.9 \times 10^{-5}$ & 2 & 1 \\
UK & -0.337 & 0.055 & 1 & - \\
USA & - & - & - & 1 \\
Region & & & & - \\
\hline Australasia & -0.329 & 0.062 & 1 & - \\
BRICS & -0.314 & 0.075 & 2 & 1 \\
Europe & - & - & - & - \\
North America & - & - & - & \\
All Countries & -0.434 & 0.012 & 1 & \\
Average & -0.377 & 0.050 & - & \\
\hline
\end{tabular}

Table 3. The results from ECS threshold tests, using periods of high ECS, for each country, region, and all countries analysed. The strongest significant correlation, having a $p$-value of less than 0.1 , between ECS and GDP change, are given along with the corresponding $p$-value. The estimated ECS threshold is recorded along with the year lag applied to obtain the correlation.

\begin{tabular}{ccccc}
\hline Country & Strongest Correlation Coefficient & $p$-Value & ECS Threshold & Year Lag \\
\hline Australia & -0.681 & 0.004 & $3.4 \%$ (Lower Threshold) & 1 \\
Brazil & -0.898 & 0.038 & $6.5 \%$ & 2 \\
Canada & -0.943 & 0.005 & $6.8 \%$ & 1 \\
China & -0.842 & 0.018 & $25.2 \%$ & 1 \\
France & -0.949 & 0.013 & $4 \%$ & 1 \\
Germany & -0.854 & 0.065 & $5.1 \%$ & - \\
India & - & - & - & 2 \\
Italy & -0.854 & 0.029 & $3.9 \%$ & 1 \\
Mexico & -0.958 & 0.004 & $6.4 \%$ & 1 \\
New Zealand & -0.690 & 0.085 & $4.8 \%$ & 1 \\
Russia & -0.866 & 0.026 & $11.6 \%$ & 1 \\
South Africa & -0.855 & 0.014 & $4.4 \%$ & 1 \\
Spain & -0.855 & 0.030 & $4.9 \%$ & 1 \\
UK & -0.900 & 0.014 & $4.9 \%$ & 1 \\
USA & -0.939 & 0.005 & & 2 \\
\hline Region & & & $9.9 \%$ & 1 \\
\hline Australasia & -0.981 & 0.091 & $3 \%$ (Lower Threshold) & 1 \\
BRICS & -0.915 & 0.011 & $6.3 \%$ & - \\
Europe & -0.857 & 0.007 & $5.1 \%$ & \\
North America & -0.833 & 0.020 & - & \\
All Countries & -0.857 & 0.029 & 0.027 & \\
Average & -0.870 & & & \\
\hline
\end{tabular}

The study found that for most countries, the estimated ECS threshold values for the first period of high ECS (1978-1985) were generally higher than that of the threshold that was established during the second period of high ECS (2005-2010). Economies were severely affected by the financial crises of 2008, drastically reducing the demand and the price of energy. If this did not occur, the same threshold may have been reached. Another reason could be that economies have become more dependent on energy, especially low-cost energy, to generate growth. They are thus more greatly affected by high ECS 
values. Many nations experience 'aftershocks' after an economic recession, which could be validated by the high energy costs that have not yet reduced to a low enough level to stimulate economies.

An interesting finding was that the effect of a lower ECS threshold may also occur, leading to the situation where economic growth is highly dependent on low ECS values. Evidence of this was found during the analysis of India, Spain, Italy, and Australia. Significantly, negative correlations between the economy and ECS values were established only for periods of low ECS in Australia. As it is a major exporter of coal, especially to the Asian market, the results of Australia's ECS threshold may not reflect the direct effect of ECS on the country, but rather how the global trend of energy costs affects this country's economy.

\subsection{ECS vs Societal Development}

\subsubsection{ECS vs GNI Per Capita}

New to this field of research, this study found that an ECS threshold also exists for GNI per capita change, much like GDP change. Throughout the study, GNI per capita had a greater reaction to varying ECS. Tables 4 and 5 provide a summary of the correlations between GNI per capita change and ECS for each country. The fact that average correlations established between GNI per capita change and ECS $(-0.411)$ were stronger than the average correlations between GDP change and ECS $(-0.377)$ indicates that ECS impacts societal growth more so than it does on the economy.

Table 4. The results from the correlation tests between the GNI per capita change and ECS for the different countries, regions and all countries analysed. The strongest significant correlation, obtaining a $p$-value of less than 0.1 , is published, with its corresponding $p$-value. The year lag that this correlation is obtained is also published alongside. As significant correlations could be obtained for multiple year lags, the year lags applied to the GNI per capita change that produced significant results are displayed in the last column.

\begin{tabular}{ccccc}
\hline Country & Strongest Correlation Coefficient & $p$-Value & Year Lag & Year Lags Affected \\
\hline Australia & -0.343 & 0.051 & 1 & 1 \\
Brazil & - & - & - & - \\
Canada & -0.354 & 0.043 & 1 & 1 \\
China & - & - & - & - \\
France & -0.315 & 0.074 & 1 & 1 \\
Germany & - & - & - & - \\
India & - & - & - & - \\
Italy & -0.381 & 0.029 & 1 & - \\
Mexico & - & - & - & - \\
New Zealand & - & - & - & - \\
Russia & - & - & - & - \\
South Africa & - & - & - & $0,1,2,3$ \\
Spain & -0.671 & $1.9 \times 10-5$ & 1 & 1 \\
UK & -0.301 & 0.088 & 1 & - \\
USA & - & - & - & \\
Region & & & & $0,1,2$ \\
Australasia & -0.394 & 0.023 & 1 & - \\
BRICS & -0.488 & 0.004 & 2 & 1 \\
Europe & - & - & - & - \\
North America & -0.319 & 0.071 & 1 & \\
All Countries & -0.539 & 0.001 & 1 & \\
Average & -0.411 & 0.038 & - & -3 \\
\hline
\end{tabular}


Table 5. The results from ECS threshold tests, using periods of high ECS, for each country, region, and all countries analysed. The strongest significant correlation, having a $p$-value of less than 0.1 , between ECS and GNI per capita change are given along with the corresponding $p$-value. The estimated ECS threshold is recorded, along with the year lag applied to obtain the correlation.

\begin{tabular}{ccccc}
\hline Country & Highest ECS Correlation & $p$-Value & ECS Threshold & Year Lag \\
\hline Australia & -0.655 & 0.006 & $3.4 \%$ (Lower Threshold) & 1 \\
Brazil & -0.884 & 0.047 & $6.5 \%$ & 2 \\
Canada & -0.907 & 0.013 & $6.8 \%$ & 1 \\
China & -0.836 & 0.019 & $25.2 \%$ & 1 \\
France & -0.940 & 0.018 & $4 \%$ & 1 \\
Germany & -0.835 & 0.078 & $5.1 \%$ & 1 \\
India & - & - & - & - \\
Italy & -0.885 & 0.019 & $3.9 \%$ & 1 \\
Mexico & -0.934 & 0.006 & $6.4 \%$ & 0 \\
New Zealand & -0.817 & 0.025 & $4.8 \%$ & 1 \\
Russia & -0.860 & 0.028 & $11.6 \%$ & 1 \\
South Africa & -0.923 & 0.003 & $3.4 \%$ & 1 \\
Spain & -0.962 & 0.002 & $4.3 \%$ & 1 \\
UK & -0.910 & 0.011 & $4.9 \%$ & 1 \\
USA & -0.960 & 0.002 & $4.9 \%$ & 1 \\
Region & & & & 2 \\
\hline Australasia & -0.972 & 0.028 & $3 \%($ Lower Threshold) & 1 \\
BRICS & -0.908 & 0.012 & $9.9 \%$ & 1 \\
Europe & -0.874 & 0.005 & $6.3 \%$ & - \\
North America & -0.904 & 0.013 & $5.1 \%$ & $-7 \%$ \\
All Countries & -0.880 & 0.021 & - & \\
Average & -0.887 & 0.029 & & \\
\hline
\end{tabular}

\subsubsection{ECS vs. Health and Education Indices}

Splitting the HDI into its three components provided insight into how the ECS affects income, health, and education levels. ECS has been shown to have a strong correlation with the GNI per capita and GDP, though however, not with the health and education indices for all the countries analysed. When thought about in a mechanistic manner, if a government is spending more money on energy sources, it will have less money for education and health expenditure for its people. On a societal level, people may have to sacrifice health or education benefits to pay for energy sources. However, there are few reasons for why the lack of correlations obtained for between ECS and the health and education indices could counteract this 'logical' approach. The first is that health and education systems of nations in this study are extremely good, and they do not vary in the face of varying energy expenditure. These two systems may be given a higher priority than economic growth, and, therefore, are not drastically affected by any budget cuts. Advances in technology may also have had a more influential role in these two sectors. It has become much easier to access information thanks to the ever-growing communications market. The discovery of penicillin has had major effects on world health. Not only is it extremely effective in combatting disease in humans, it is also used widely in the food sector, allowing food supplies to drastically increase. These innovations may be more significant than the effect that ECS has on health and education. Another reason could be that the indices used to monitor the state of health and education of the countries may not have been responsive enough show any fluctuations. Furthermore, the education and health data points are only ever taken every five years, with the points in between being interpolations.

\subsection{Time Lag Effects}

Previous studies use a one year lag when comparing ECS and the US economy [2,13,14]. King [13] used a one year lag to obtain any correlations between ECS and GDP change, for a range of countries. 
Although the strongest correlations were obtained with these time lags for many of the countries in this analysis, this study showed that this is certainly is not the case for all. Significant correlations were also found for zero, two, and three-year lags for many countries and regions in this analysis. The inclusion of these lags reveals the duration of time that is needed for an economy or society to respond to high ECS, indicated by the time lag that is used to establish the ECS thresholds. The effects of ECS may be immediate, as seen in the case of New Zealand and Spain, or it may take up to two years for the effects of high ECS to emerge, as seen in Italy. The analysis of the BRICS nations revealed that a two-year time lag during periods of high ECS brought the sharpest response to GDP and GNI per capita change. This is indicative of global market dynamics, as these nations are dependent on offshore investment to stimulate growth. It may take more time for the lack of investment, due to high ECS, to have its effects on a developing nation. In general, the second period of high ECS (2005-2010) brought a much more immediate response by countries' GDP and GNI, than in the first period of high ECS (1978-1985). This provides further evidence that nations have become more dependent on energy, especially low cost energy, to generate development.

The consideration of multiple-year lags also revealed the duration of time that is needed by an economy or society to recover from a period of high ECS, as seen by significant correlations obtained for multiple time lags for the overall correlation tests. Significant correlations between the GNI per capita change and ECS were often established for multiple-year lags in the country analysis, but more so in the regional analysis and the 'All Countries' analysis. These results indicate the importance of considering high ECS, as it can constrict economic and social growth for years after energy costs have been reduced. The results from the 'All Countries' analysis showed that a high ECS peak can effect societal growth for up to four years.

\subsection{Regional Analysis}

The regional analysis of this study showed that a higher percentage of the correlations obtained, in both the overall correlation test and the ECS threshold test, were seen to be stronger and statistically significant for the regional analysis than for the country analysis. Furthermore, these results were seen in places where the individual nations making up the region did not produce any correlations in the same places as the region. None of the BRICS nations, for example, established significant overall correlations between ECS and GDP change, as well as ECS and GNI per capita change. When all the data were summarised and analysed, it reflected strong correlations for many year lags. Australasia provided another good example of this, as ECS thresholds were established for three different time periods for the region, but only one was established for each nation. A possible reason for this occurrence could be that by combining all the data, a lot of the 'noise' in each country is cancelled out. Changes in economic and social growth within a country can happen for a variety of reasons. Political and social instabilities occur in all countries, but perhaps even more so in third world nations. By aggregating the data, we are left with the weighted average GDP and GNI per capita change where the variations in these indices, due to slight political and social changes, are flattened out. When aggregated, the combined data gives a better reflection of how variations in energy expenditure can massively affect economic and social conditions within emerging markets.

As one of the objectives of this study was to identify certain regions with similar ECS dynamics, country comparisons were made throughout this study:

- The nations from the Mediterranean region (Italy, France, and Spain), as well as South Africa, were all seen to have similar traits. Including similar ECS shapes over the period being analysed, very similar estimated ECS thresholds, as well as correlations with roughly the same magnitude. Italy, France, and Spain, situated very close together, could make up a region of similar economic and social dynamics to ECS. The actual prices to produce energy in this region may be very similar to all countries. Two possibilities could give reasons for why South Africa's ECS curve is similar to those of the Mediterranean nations. One is the climate is similar. The second is that the Apartheid regime may have split the South African nation into two. One part of society controls most the 
wealth, creating an economy similar to the dynamics of a European country. The majority of society was tasked with providing cheap labour in order for big business to succeed. Contributing to this is the fact that many of South Africa's poor use biofuel for their energy needs. By excluding biofuels, this study focusses more on the nation's wealthy residential and business sector.

- China and Russia make up another group of countries with similar dynamics. Both these nations had extremely high ECS peaks around 1980 (40\% and 34\%, respectively) and a very high average ECS value throughout the period, as well as resilience towards high ECS values. Reasons explaining these traits included the fact that these countries have large amounts of fuel stocks that supply their nation with fuel. These nations also included planned economy principles that may have allowed their countries to react differently in the face of high ECS prices.

- Similarities were also noted for a group of countries that were not situated close together geographically. These were Germany, the UK, and the USA. The estimated ECS thresholds for these three countries, for the two periods of high ECS, were very similar $(5.1 \%, 4.9 \%$, and $4.9 \%$, respectively) Furthermore, these countries had much stronger correlations for the second peak in ECS, even though the estimated ECS threshold for the second period was lower than that of the first. Although the energy mixes of these countries had similarities, a more plausible reason for the common dynamics could be the high industrial share in the global economy that these countries had throughout the period being analysed. The 'All Country' ECS dynamics were very similar to these nations, indicating that a collapse in these three economies will cause widespread damage globally.

\section{Conclusions}

The study found that there is a correlation between high ECS and economic development, and that each country has individual dynamics to ECS. The existence of an ECS threshold, as suggested by Bashmakov [12], was validated in many countries and regions, with very strong correlation coefficients being obtained for periods of high ECS.

This study further investigated the unique characteristics of each country chosen, with multiple time lags being investigated. It was found that high ECS values correlate to low economic development in 14 out of the 15 countries. However, countries may also be deeply affected by low global energy prices, as in the case of Australia, as low energy stimulates exports and boosts economies. There are also varying time lags between high ECS and the effects on economic growth, with some countries appearing to react instantly to high ECS (New Zealand and India), and some seem to take longer (Italy).

Acknowledging the importance of social development, this study investigated the effect of ECS on human development and found mixed results. ECS had a very strong correlation to GNI per capita change, much stronger than the correlation between ECS and GDP change. This revelation is very evident in the regional analysis and, most noteworthy, the 'All Countries' analysis, which is shown to give a fair representation on global ECS dynamics. Not only were the correlations stronger, but they also affected the GNI per capita change for a period of four years. The use of ECS may be a good tool for stimulating economic growth, but more importantly, it stimulates human development in the form of income levels. On the other hand, ECS did very little in affecting the education and health indices of each country. This could suggest that the health and education systems of each country are resistant to a fluctuating ECS. Considering the drastic effect that ECS had on GNI per capita levels, it is more likely that these indices do not accurately represent that relationship between ECS and health and education levels.

This study found that economic and human development are affected differently by ECS in different regions of the world. Very little overall correlation exists between economic and social development for North America and Europe. These regions, however, are deeply affected by an ECS threshold. The BRICS nations obtained significant correlations for both the overall correlation test as well as the ECS threshold test, with the strongest correlations coming after a two-year lag. Australasia seems to experience a lower ECS threshold, below which ECS levels drastically affect GDP and GNI 
per capital change. Much like the BRICS nations, GNI per capita change is affected more severely than GDP change in Australasia. It was found that stronger, and more statistically significant correlations were obtained when conducting regional analyses. The combined data gives a better reflection of how variations in ECS can massively affect economic and social conditions. Many of the fluctuations in economic and social change, not caused by varying ECS, are evened out when using regional data.

An investigation was made into the influences that could affect the dynamics of ECS on a country's economic and social development. The effects may be localised to a specific region; for example, the Mediterranean region and the Asian region of Russia and China. There are many other factors that can play a vital role, such as a country's energy mix, economic situation, and political history. The similarities in the results of Germany, the UK, and the USA show that countries from vastly different backgrounds can all react in a similar fashion, due to economic positions in the globe. The study showed that regional data is useful in cementing the effects of ECS on social and economic development; however, country-level studies should be coordinated in order to establish specific thresholds, correlations, and so forth. This is vital information, should energy policy be made at a national level. Once overall correlations and thresholds are established, countries can develop energy policies that can avoid economic and social decline. Understanding the effects of ECS on social and economic development are essential in assisting a transition to cleaner energy sources in a sustainable manner.

Author Contributions: R.R. performed the literature review and analyses, and wrote the paper. J.K.M., A.C.B. and M.K.H. provided expertise and guidance on the research concept and methodology, confirmed the analyses, and assisted in writing the paper.

Funding: This research was funded by National Research Foundation of South Africa with grant number [99103].

Conflicts of Interest: The authors declare no conflict of interest.

\section{References}

1. Stern, D.I. The role of energy in economic growth. Ann. N. Y. Acad. Sci. 2011, 1219, 26-51. [CrossRef] [PubMed]

2. Aucott, M.; Hall, C. Does a Change in Price of Fuel Affect GDP Growth? An Examination of the U.S. Data from 1950-2013. Energies 2014, 7, 6558-6570. [CrossRef]

3. Heun, M.K.; Santos, J.; Brockway, P.E.; Pruim, R.; Domingos, T.; Sakai, M. From Theory to Econometrics to Energy Policy: Cautionary Tales for Policymaking Using Aggregate Production Functions. Energies 2017, 10, 203. [CrossRef]

4. Ozturk, I. A literature survey on energy-growth nexus. Energy Policy 2010, 38, 340-349. [CrossRef]

5. Moore, H. Global Prosperity and Sustainable Development Goals. J. Int. Dev. 2015, 27, 801-815. [CrossRef]

6. Fioramonti, L. Gross Domestic Problem: The Politics behind the World's Most Powerful Number; Zed Books: London, UK, 2013.

7. UNDP. Human Development Report 2005; Hoechstetter Printing: New York, NY, USA, 2005.

8. D'amelio, M.; Garrone, P.; Piscitello, L. Can Multinational Enterprises Light up Developing Countries? Evidences from the Access to Electricity in sub-Saharan Africa. World Dev. 2016, 88, 12-32. [CrossRef]

9. Kanagawa, M.; Nakata, T. Analysis of the energy access improvement and its socio-economic impacts in rural areas of developing countries. Ecol. Econ. 2007, 62, 319-329. [CrossRef]

10. Lenz, L.; Munyehirwe, A.; Peters, J.; Sievert, M. Does Large-Scale Infrastructure Investment Alleviate Poverty? Impacts of Rwanda's Electricity Access Roll-Out Program. World Dev. 2017, 89, 88-110. [CrossRef]

11. Nkomo, J. Energy use, poverty and development in the SADC. J. Energy South. Afr. 2007, 18, 10-17.

12. Bashmakov, I. Three laws of energy transitions. Energy Policy 2007, 35, 3583-3594. [CrossRef]

13. King, C. Comparing World Economic and Net Energy Metrics, Part 3: Macroeconomic Historical and Future Perspectives. Energies 2015, 8, 12997-13020. [CrossRef]

14. Fizaine, F.; Court, V. Energy expenditure, economic growth, and the minimum EROI of society. Energy Policy 2016, 95, 172-186. [CrossRef]

15. IEA. World Energy Outlook 2016; IEA: Paris, France, 2016. 
16. IEA. Energy and Air Pollution 2016; IEA: Paris, France, 2016.

17. Arshad, A.; Zakaria, M.; Xi, J. Energy prices and economic growth in Pakistan: A macro-economic analysis. Renew. Sustain. Energy Rev. 2015, 55, 25-33. [CrossRef]

18. Murphy, D.; Hall, C. Energy return on investment, peak oil, and the end of economic growth. Ann. N. Y. Acad. Sci. 2011, 1219, 52-72. [CrossRef] [PubMed]

19. Chang, T.; Huang, C.; Lee, M. Threshold effect of the economic growth rate on the renewable energy development from a change in energy price: Evidence from OECD countries. Energy Policy 2009, 37, 5796-5802. [CrossRef]

20. Gan, J.; Smith, C. Drivers for renewable energy: A comparison among OECD countries. Biomass Bioenergy 2011, 35, 4497-4503. [CrossRef]

21. Worldbank. Available online: http:/ / databank.worldbank.org/data (accessed on 15 May 2017).

22. OECD Database. Available online: http://www.oecd-ilibrary.org.ez.sun.ac.za/statistics (accessed on 16 May 2017).

23. United Nations Development Programme. Available online: http://hdr.undp.org/en/content/expectedyears-schooling-children-years (accessed on 18 May 2017).

(C) 2018 by the authors. Licensee MDPI, Basel, Switzerland. This article is an open access article distributed under the terms and conditions of the Creative Commons Attribution (CC BY) license (http:/ / creativecommons.org/licenses/by/4.0/). 